Article

\title{
Carbon Black-Carbon Nanotube Co-Doped Polyimide Sensors for Simultaneous Determination of Ascorbic Acid, Uric Acid, and Dopamine
}

\author{
Yue Wang ${ }^{1, *(\mathbb{D}}$, Tian Yang ${ }^{1}$, Yasushi Hasebe ${ }^{2}$, Zhiqiang Zhang ${ }^{1}$ and Dongping Tao ${ }^{3, *}$ \\ 1 School of Chemical Engineering, University of Science and Technology Liaoning, 185 Qianshan Middle \\ Road, High-Tech Zone, Anshan 114051, Liaoning, China; yt851991425@163.com (T.Y.); \\ zhangzhiqiang@ustl.edu.cn (Z.Z.) \\ 2 Department of Life Science and Green Chemistry, Faculty of Engineering, Saitama Institute of Technology, \\ 1690 Fusaiji, Fukaya, Saitama 369-0293, Japan; hasebe@sit.ac.jp \\ 3 School of Mineral Engineering, University of Science and Technology Liaoning, 185 Qianshan Middle Road, \\ High-Tech Zone, Anshan 114051, Liaoning, China \\ * Correspondence: wangyue@ustl.edu.cn (Y.W.); daniel.dtao@gmail.com (D.T.); \\ Tel.: +86-412-5929269 (Y.W.); +86-412-5929488 (D.T.)
}

Received: 7 August 2018; Accepted: 10 September 2018; Published: 12 September 2018

check for updates

\begin{abstract}
Carbon black (CB) and carbon nanotube (CNT) co-doped polyimide (PI) modified glassy carbon electrode (CB-CNT/PI/GCE) was first prepared for the simultaneous determination of ascorbic acid (AA), dopamine (DA), and uric acid (UA). The CB-CNT/PI/GCE exhibited persistent electrochemical behavior and excellent catalytic activities. Cyclic voltammetry $(\mathrm{CV})$ and differential pulse voltammetry (DPV) were used for the simultaneous detection of AA, DA, and UA in their ternary mixture. The peak separations between $\mathrm{AA}$ and DA, and DA and UA, are up to $166 \mathrm{mV}$ and $148 \mathrm{mV}$, respectively. The CB-CNT/PI/GCE exhibited high sensitivity to DA and UA, with the detection limit of $1.9 \mu \mathrm{M}$ and $3 \mu \mathrm{M}$, respectively. In addition, the CB-CNT/PI/GCE showed sufficient selectivity and long-term stability, and was applicable to detect AA, DA, and UA in human urine sample.
\end{abstract}

Keywords: polyimide; simultaneous determination; uric acid; dopamine; ascorbic acid

\section{Introduction}

Dopamine (DA) is an important catecholamine neurotransmitter for message transfer in the mammalian central nervous system [1]. It plays an important role to regulate physiological processes and has direct effects on human emotion [2-4]. Low concentration level of DA is associated with neurological disorders such as Parkinson's disease, schizophrenia, and Huntington's disease [5]. Uric acid (UA) is the primary end product of purine metabolism that can be found in different concentrations in urine and human blood plasma [6]. The abnormal concentration level of UA will lead to several diseases such as leukemia, pneumonia [7], hyperuricemia, and gout [8]. Ascorbic acid (AA) exists in the human body, prevents scurvy, and is known to participate in several biological reactions. The accurate and rapid determination of these three species is highly demanded in the medical diagnosis. However, UA, AA, and DA always coexist in real biological samples. In addition, they show nearly the same oxidation potential on traditional electrodes [9]. Therefore, the development of a selective method for the simultaneous detection of the mixture is highly desirable [10].

On account of the comprehensive consideration of in vivo environment, it is necessary to develop a simultaneous, rapid, and accurate analytical method for the determination of the ternary mixture of AA, DA, and UA. Electrochemical techniques are the most used method for the quantitative 
determination of AA, DA, and UA with excellent accuracy. Numerous materials such as carbon nanotube [11,12], graphene [13-15], graphene oxide [16], $\mathrm{MoS}_{2}$ [2,9] metal and metal oxide [17-19], conducting polymer [20,21], boron-doped diamond [22], silica gel [23], and nafion [24] have been used for the modification of electrodes to realize the simultaneous detection of AA, DA, and UA. Polyimide (PI) is considered an ideal polymer material due to its high thermal stability, excellent chemical and physical properties, and good adhesion properties [25]. Typically, PI is widely used in the semiconductor industry for passivation or dielectric layer [26]. The highly-insulating property of PI, however, restricts the application in electronic devices of PI.

In this study, we suggest a method to fabricate a thin PI composite film on glassy carbon electrode (GCE). The PI was doped with the hybrid material of carbon black (CB) and carbon nanotube (CNT). By taking advantages of high electronic conductivity of CB and CNT, the CB-CNT/PI composite exhibits excellent responses to the simultaneous detection of AA, DA, and UA. Owing to the desirable structure and stability of PI, the present CB-CNT/PI/GCE exhibits good selectivity and long-term stability.

\section{Materials and Methods}

\subsection{Reagents and Materials}

The reagent 4,4'-(Hexafluoroisopropylidene) diphthalic dianhydride (6FDA) was purchased from ChinaTech (Tianjin, China) Chemical Co. Ltd., which was recrystallized from acetic anhydride, and vacuum dried before using. The reagent 9,9'-bis(4-hydroxy phenyl) fluorene (BHF) was purchased from Sinosteel Anshan Research Institute of Thermo-energy Co. Ltd., Anshan, China. $N, N^{\prime}$-dimethylacetamide (DMAc), Pd/C (10\%), hydrazine hydrate, acetone, nitric acid, ethanol, acetic anhydride, pyridine, $\mathrm{K}_{2} \mathrm{HPO}_{4}, \mathrm{KH}_{2} \mathrm{PO}_{4}$, uric acid (UA), ascorbic acid (AA) and dopamine (DA), urea, glucose, fructose, maltose, hydrogen peroxide $\left(\mathrm{H}_{2} \mathrm{O}_{2}\right)$, potassium chloride $(\mathrm{KCl})$, ironic chloride $\left(\mathrm{FeCl}_{3}\right)$, ammonium chloride $\left(\mathrm{NH}_{4} \mathrm{Cl}\right)$, sodium sulphate $\left(\mathrm{Na}_{2} \mathrm{SO}_{4}\right)$, sodium chloride $(\mathrm{NaCl})$, and citric acid were purchased from Sinopharm Chemical Reagent Co., Ltd., Beijing, China. DMAc was dried using anhydrous molecular sieves before using. Carbon black (CB) was obtained from CABOT Corporation and used as received. Carbon nanotube (CNT) was obtained from Showa Denko Co. Ltd., Tokyo, Japan. Glassy carbon electrode (GCE, $3.0 \mathrm{~mm}$ in diameter) was obtained from Shanghai Chen Hua Instrument Co. Ltd., Shanghai, China. A $0.1 \mathrm{M}$ phosphate buffer solution (PBS, prepared by using $\mathrm{K}_{2} \mathrm{HPO}_{4}$ and $\mathrm{KH}_{2} \mathrm{PO}_{4}$ ) was used to prepare electrolyte. Doubly distilled water was used throughout the experiments. All other chemicals were of analytical grade and were used without further purification.

\subsection{Apparatus}

The $\mathrm{X}$-ray diffraction (XRD) pattern was taken from $5^{\circ}$ to $60^{\circ}(2 \theta$ value) with $\mathrm{Cu}-\mathrm{K} \alpha$ radiation $\left(\lambda=1.541 \AA\right.$ ) by an $X^{\prime}$ Pert Powder X-ray diffractometer ( $X^{\prime}$ Pert PRO, PANalytical, Almelo, The Netherlands). Fourier transform infrared spectrometry (FT-IR) spectra were measured using a Nicolet IS 10 (Thermo Scientific, Madison, WI, USA) equipped in the range of $500-4000 \mathrm{~cm}^{-1}$, the average scanning frequency of the instrument was 16 times. The synthesized monomer and polyimide were analyzed by proton nuclear magnetic resonance $\left({ }^{1} \mathrm{H}-\mathrm{NMR}\right)$ spectra on a Bruker Advance-AV $500 \mathrm{MHz}$ instrument (Bruker, Karlsruhe, Germany) in deuterated dimethyl sulfoxide. The morphologies of the modified electrode surfaces were observed using the field emission scanning electron microscope (FE-SEM, IIGMA-HD, ZEISS, Oberkochen, Germany). Electrochemical measurements were performed with a CHI 750D workstation (Shanghai Chenhua, Shanghai, China). A conventional three electrode system with PI modified GCE as working electrode, a $1.0 \mathrm{~mm}$ diameter of $\mathrm{Pt}$ wire as counter electrode, and $\mathrm{Ag} / \mathrm{AgCl}$ (sat. $\mathrm{KCl}$ ) as reference electrode was employed in this study. All measurements were performed in air at room temperature of approximately $20^{\circ} \mathrm{C}$. 


\subsection{Synthesis of PI}

\subsubsection{The Synthesis of 9,9'-Bis[4-(4-nitro-2-hydroxybenzoxyl) phenyl] Fluorene (BNHOPF)}

The BHF (1 mol) was reacted with 5-fluoro-2-nitrophenol $(2 \mathrm{~mol})$ by nucleophilic aromatic substitution in the presence of potassium carbonate $(2 \mathrm{~mol})$ and DMAc under $12 \mathrm{~h}$ of heating. The mixture was poured into distilled water for cooling, the yellow solid compound was filtered and dried. (HPLC: $99.8 \%$, yield: $80.25 \%$, melting point: $185.2^{\circ} \mathrm{C}$ ). The detailed reaction procedure is shown in the first step of Figure S1. Figure S2 is the ${ }^{1} \mathrm{H}-\mathrm{NMR}$ spectrum of BNHOPF $(\delta 11.14(\mathrm{~s}, 2 \mathrm{H}), 7.97(\mathrm{td}$, $J=6.1,3.0 \mathrm{~Hz}, 4 \mathrm{H}), 7.52(\mathrm{~d}, J=7.7 \mathrm{~Hz}, 2 \mathrm{H}), 7.45(\mathrm{t}, J=7.4 \mathrm{~Hz}, 2 \mathrm{H}), 7.38(\mathrm{~s}, 2 \mathrm{H}), 7.23(\mathrm{dd}, J=8.7,2.0 \mathrm{~Hz}$, $4 \mathrm{H}), 7.14-7.07(\mathrm{~m}, 4 \mathrm{H}), 6.52(\mathrm{dd}, J=9.1,7.2 \mathrm{~Hz}, 4 \mathrm{H})$.

\subsubsection{The Synthesis of 9,9'-Bis[4-(4-amino-2-hydroxybenzoxyl) phenyl] Fluorene (BAHOPF)}

Thirty milliliters of ethanol, $0.01 \mathrm{~mol}$ (BNHOPF), and $0.25 \mathrm{~g}$ Pd/C were mixed in a three-necked flask. Twenty milliliters of hydrazine hydrate were dropped into the three-necked flask with a constant pressure funnel within $1 \mathrm{~h}$. The reaction was fulfilled after heating for $12 \mathrm{~h}$. The white crystals were obtained after recrystallization (HPLC: $99.2 \%$, yield: $87.5 \%$, melting point: $280.3{ }^{\circ} \mathrm{C}$ ). The reaction procedure is shown in the second step of Figure S1. Figure S3 is the ${ }^{1} \mathrm{H}-\mathrm{NMR}$ spectrum of BAHOPF $(\delta$ $9.25(\mathrm{~s}, 2 \mathrm{H}), 7.91(\mathrm{~d}, J=7.5 \mathrm{~Hz}, 2 \mathrm{H}), 7.49-7.36(\mathrm{~m}, 5 \mathrm{H}), 7.31(\mathrm{t}, J=7.5 \mathrm{~Hz}, 3 \mathrm{H}), 7.03(\mathrm{~d}, J=8.5 \mathrm{~Hz}, 5 \mathrm{H})$, $6.75(\mathrm{~d}, J=8.4 \mathrm{~Hz}, 5 \mathrm{H}), 6.55(\mathrm{~d}, J=8.3 \mathrm{~Hz}, 2 \mathrm{H}), 6.34(\mathrm{~d}, J=2.5 \mathrm{~Hz}, 2 \mathrm{H}), 6.26(\mathrm{dd}, J=8.5,2.5 \mathrm{~Hz}, 2 \mathrm{H}))$.

\subsubsection{Preparation of Polyimide (PI)}

The preparation process of polyimide is shown in Figure S4. Briefly, BAHOPF (10 mmol) was dissolved in DMAc in a three-necked flask under nitrogen atmosphere. Subsequently, the reaction mixture was cooled to $0{ }^{\circ} \mathrm{C}$ until the solid dissolved entirely. Then, 6FDA (10 mmol) was added immediately to the mixture and stirred for $12 \mathrm{~h}$ in $\mathrm{N}_{2}$ atmosphere to obtain a viscous poly (amic acid) solution. Finally, the solution was poured into methanol to obtain a white precipitate, which was collected by filtration and vacuum dried at $150^{\circ} \mathrm{C}$ for $12 \mathrm{~h}$.

\subsubsection{Fabrication Procedures of the CB-CNT/PI/GCE}

PI (30 mg) was diluted in DMAc solvent $(0.57 \mathrm{~g})$ and sonicated for $30 \mathrm{~min}$ to make a homogeneous solution. The CB solution was prepared by putting $15 \mathrm{mg}$ of $\mathrm{CB}$ into $0.5 \mathrm{~mL}$ DMAc and sonicated for $30 \mathrm{~min}$. The CNT solution was prepared by putting $15 \mathrm{mg}$ of CNT into $0.5 \mathrm{~mL}$ DMAc and sonicated for $30 \mathrm{~min}$. Then the CB solution was mixed with CNT solution (v:v=1:1) and sonicated for $30 \mathrm{~min}$. The PI solution was mixed with the CB-CNT mixture and sonicated for $30 \mathrm{~min}$ which donated as CB-CNT/PI solution. The GCE surface was polished successively with 1.0, 0.3, $0.05 \mu \mathrm{m} \alpha$-alumina slurries to make a shiny surface. The cleaned GCE was rinsed and sonicated with distilled water and ethanol to remove any adhering alumina. Then the CB-CNT/PI solution $(10 \mu \mathrm{L})$ was dropped onto the GCE surface for 12-24 h to prepare the sensor. The fabrication of CB-CNT/PI/GCE and the detection of the substances with the electrochemical detection process is shown in Scheme 1. 


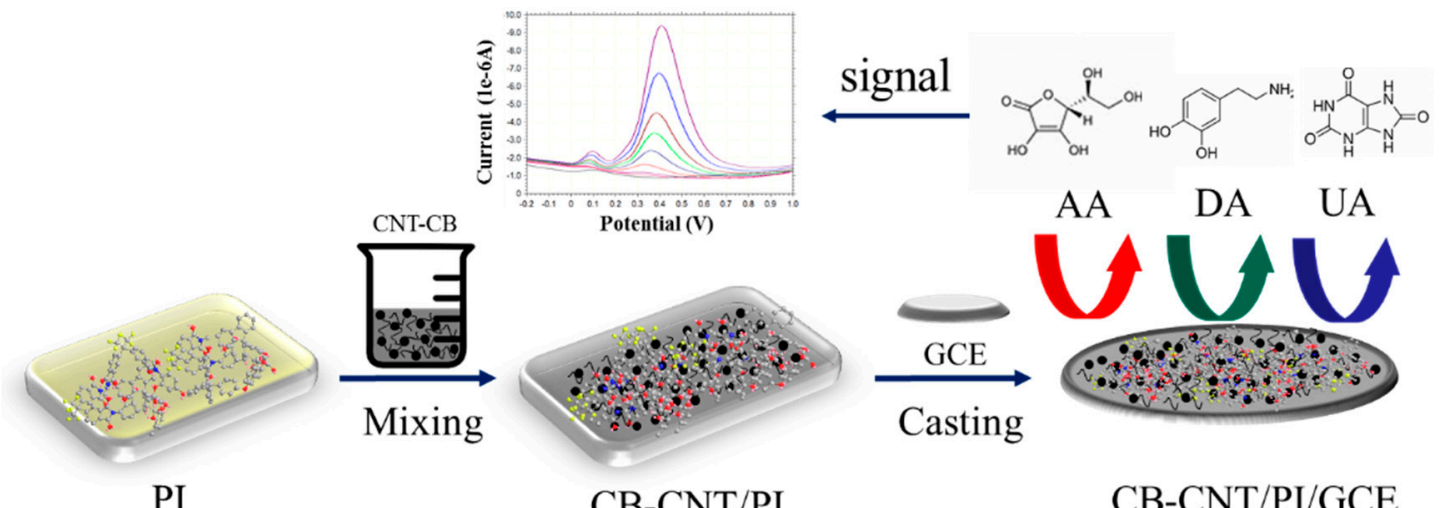

Scheme 1. Schematic representation of the fabrication of carbon black-carbon nanotube (CB-CNT)/polyimide (PI) modified glassy carbon electrode (GCE) for the detection of ascorbic acid (AA), dopamine (DA), and uric acid (UA).

\section{Results and Discussion}

\subsection{Structure Characterization of Monomers}

The structures of BNHOPF and BAHOPF were confirmed by FT-IR. Figure S5 is the FT-IR spectra of dinitro compound (BNHOPF, Figure S5a) and diamine compound (BAHOPF, Figure S5b). The disappearance on typical absorption peaks of dinitro group $\left(1585 \mathrm{~cm}^{-1}\right.$ and $\left.1330 \mathrm{~cm}^{-1}\right)$ and the appearance of characteristic absorption peaks of amine groups $\left(3382 \mathrm{~cm}^{-1}\right.$ and $\left.3318 \mathrm{~cm}^{-1}\right)$ are good evidence for the successful reduction reaction.

\subsection{Structure Characterization of Polyimide Powder}

FT-IR spectra of PI was investigated (Figure S6). The peaks around $1792 \mathrm{~cm}^{-1}, 1714 \mathrm{~cm}^{-1}$, $1383 \mathrm{~cm}^{-1}$, and $722 \mathrm{~cm}^{-1}$ correspond to asymmetric and symmetric imide ring stretching vibrations of $\mathrm{C}=\mathrm{O}, \mathrm{C}-\mathrm{N}$ vibration, and $\mathrm{C}=\mathrm{O}$ bending vibration, respectively. The broad peak around $3400 \mathrm{~cm}^{-1}$ corresponds to the asymmetric stretching of $\mathrm{O}-\mathrm{H}$ bond. [27] Furthermore, in the wide-angle $\mathrm{X}$-ray scattering patterns, the polyimides exhibit one main diffraction peak at $\mathrm{d}=0.524 \mathrm{~nm}\left(2 \theta=16.89^{\circ}\right)$ as shown in Figure S7. The d-spacing is usually considered to represent the distance between segments of different chains.

\subsection{Characterization of the CB-CNT/PI/GCE}

The SEM technique was applied to study the morphology of the CB-CNT/PI/GCE (Figure 1). The PI-modified GCE surface shows relatively flat and smooth morphology (Figure 1A). As compared with CB/PI modified GCE (Figure 1B), co-doped with CNT enhances the dopant amount, as well as the homogeneity and dispersion of dopants (Figure 1C,D). Hence, the improvement of the electrochemical properties can be expected by the doping of $\mathrm{CB}$ and CNT. 

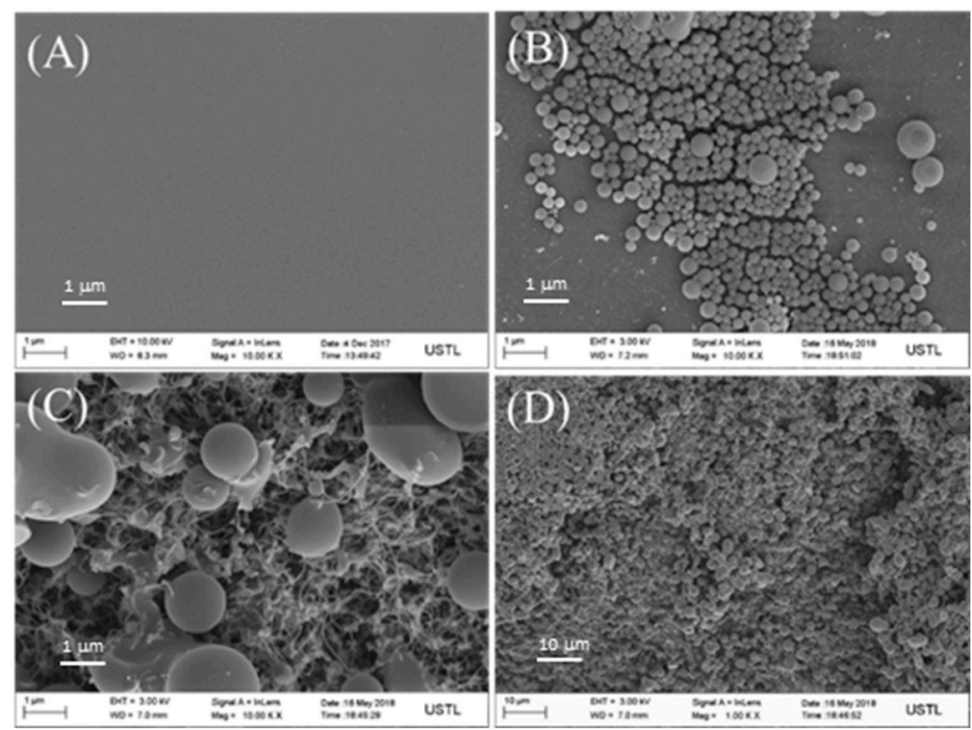

Figure 1. SEM images of polyimide (PI)/ glassy carbon electrode (GCE) (A), carbon black (CB)/PI/GCE (B), and CB-carbon nanotube (CNT)/PI/GCE (C,D).

\subsection{Electrocatalytic Oxidation of $A A, D A$, and $U A$}

The primary purpose of the present study is simultaneous detection of AA, DA, and UA. Usually, the voltammetric peaks for the oxidation of AA, DA, and UA are overlapped and hard to distinguish. To check the usefulness of the doping of $\mathrm{CB}$ and CNT within the PI, we compared the cyclic voltammetry $(\mathrm{CV})$ of ternary mixture of $\mathrm{AA}, \mathrm{DA}$, and $\mathrm{UA}$ by using various electrodes. Figure $2 \mathrm{~A}$ shows the CV responses of CB-CNT/PI/GCE (a), CB/PI/GCE (b), CNT/PI/GCE (c), and PI-GCE (d). As compared to other three electrodes, the CB-CNT co-doped PI film-modified GCE (CB-CNT/PI/GCE) (a) exhibited well-defined oxidation peaks at $-100,200$, and $360 \mathrm{mV}$, corresponding to the oxidation of AA, DA, and UA, respectively. The difference in CV responses between the CB-CNT/PI/GCE (a) and the $\mathrm{CB} / \mathrm{PI} / \mathrm{GCE}(\mathrm{b})$ seems to correspond to the differences in dopant amount on the electrode surface and surface morphology as shown in Figure 1.
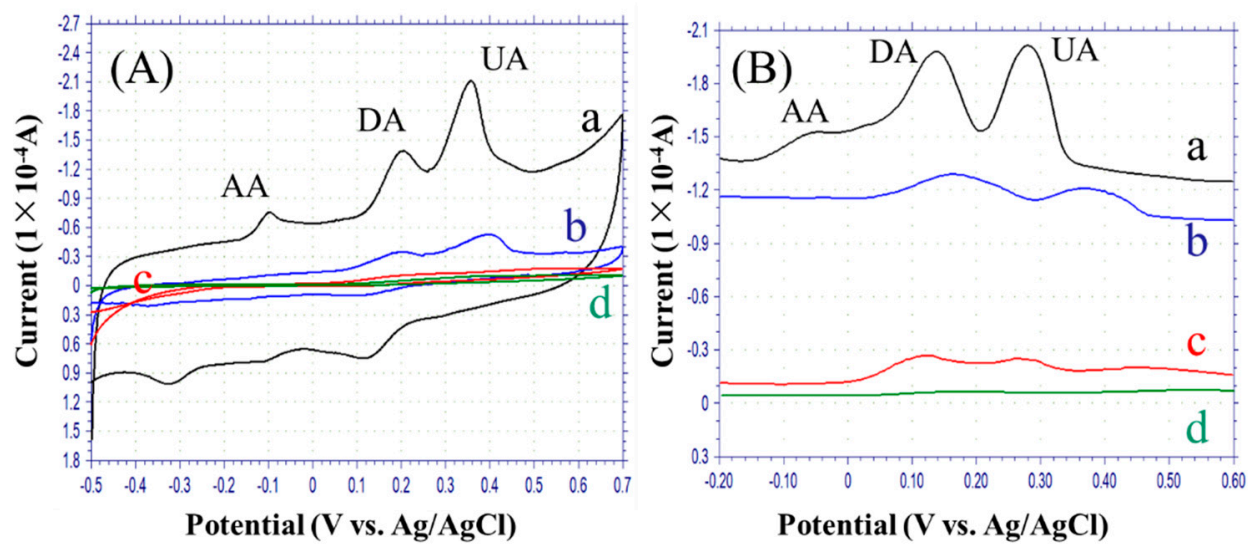

Figure 2. (A) Cyclic voltammetry (CV) responses of ternary mixture of $1.0 \mathrm{mM}$ ascorbic acid (AA), $1.0 \mathrm{mM}$ dopamine (DA), and 1.0 $\mathrm{mM}$ uric acid (UA) in $0.1 \mathrm{M}$ phosphate buffer solution (PBS) (pH 7.0) on CB-CNT/PI/GCE (a), CB/PI/GCE (b), CNT/PI/GCE (c), and PI/GCE (d) at $5 \mathrm{mV} / \mathrm{s}$; (B) differential pulse voltammetry (DPV) responses of ternary mixture of $1.0 \mathrm{mM} \mathrm{AA}, 1.0 \mathrm{mM}$ DA, and $1.0 \mathrm{mM} \mathrm{UA}$ in $0.1 \mathrm{M}$ PBS (pH 7.0) on CB-CNT/PI/GCE (a), CB/PI/GCE (b), CNT/PI/GCE (c), and PI/GCE (d) at $5 \mathrm{mV} / \mathrm{s}$. 
In general, differential pulse voltammetry (DPV) has been widely utilized for the simultaneous detection of AA, DA, and UA, due to high sensitivity and selectivity [28-30]. Figure 2B illustrates DPV responses of ternary mixture of AA, DA, and UA obtained by CB-CNT/PI/GCE (a), CB/PI/GCE (b), CNT/PI/GCE (c), and PI-GCE (d). The PI/GCE (d) did not show clear response, indicating that the doping of $\mathrm{CB}$ and $\mathrm{CNT}$ within the PI film is essential to obtain the electrochemical responses. As expected, the CB-CNT/PI/GCE (a) exhibited three well-defined anodic peaks at $-40,140$, and $280 \mathrm{mV}$. These results strongly suggest the potential ability of the CB-CNT/PI/GCE for simultaneous determination of AA, DA, and UA, based on the selective electrocatalytic behavior.

\subsection{Differential Pulse Voltammetry (DPV) for Simultaneous Detection of $A A, D A$, and $U A$}

Next, we tried individual determination of each substance in the ternary mixture with DPV. Figure 3 illustrates the DPV curves (Figure $3 \mathrm{~A}-\mathrm{C}$ ) and calibration plots (the oxidation current versus the concentration) (Figure 3D-F) obtained by the measurement of ternary mixture of AA, DA, and UA. As shown in Figure 3A-C, the oxidation peak current of AA, DA, or UA increases with the increasing of individual concentrations in the presence of the other two substrates, and the linear calculation plots are shown in Figure 3D-F. In the case of AA (Figure 3A), the broad AA peak at ca. $-50 \mathrm{mV}$ increased linearly with the increase in AA concentration (Figure 3D). In the case of DA (Figure 3B), the peak current at $+200 \mathrm{mV}$ clearly increases with the increase in DA concentration, and two linear portions can be seen in the calibration plot (Figure $3 \mathrm{E})$. In a low concentration range of DA $\left(\mathrm{C}_{\mathrm{DA}}: 3-300 \mu \mathrm{M}\right)$, the linear regression equation is $\mathrm{I}_{\mathrm{DA}}=51.84 \mathrm{C}_{\mathrm{DA}}-0.2474$, with a correlation coefficient of $\mathrm{R}^{2}=0.9993$. In a high concentration range of $\mathrm{DA}\left(\mathrm{C}_{\mathrm{DA}}: 300-2000 \mu \mathrm{M}\right)$, the linear regression yields a relationship of $I_{D A}=16.14 C_{D A}+0.3667$, with a correlation coefficient of $R^{2}=0.9987$. Similar results were observed for UA (Figure 3C,F), and two linear regions are also observed in the calibration plot (Figure 3F). The linear regression equations are $\mathrm{I}_{\mathrm{UA}}=9.8605 \mathrm{C}_{\mathrm{UA}}+0.0633\left(\mathrm{C}_{\mathrm{UA}}: 1-500 \mu \mathrm{M}, \mathrm{R}^{2}=0.9964\right)$ and $\mathrm{I}_{\mathrm{UA}}=1.9586 \mathrm{C}_{\mathrm{UA}}$ $+2.1075\left(\mathrm{C}_{\mathrm{UA}}: 500-3000 \mu \mathrm{M}, \mathrm{R}^{2}=0.9998\right)$. The observed two slopes could be explained by monolayer adsorption followed by multilayer adsorption [31], or existence of different structural layer portion within the composite CB-CNT/PI film. The lower sensitivity in the high concentration region could be caused by limited active sites of $\mathrm{CB}$ and CNT for the oxidation of DA and UA [32]. As shown in Figure $3 \mathrm{~A}, \mathrm{D}$, AA has only one linear region from 4 to $26 \mathrm{mM}$, probably because the second region is located in higher concentrations. The sensitivity of AA is much lower than DA and UA. This tendency has also been reported by other carbon-nanomaterials-based electrodes [31,33-35]. The approach of negatively-charged AA to the electrode surface through the PI film probably inhibited by the electric repulsion with negative charge of AA and carboxyl group of the graphite edge of CB and CNT. 

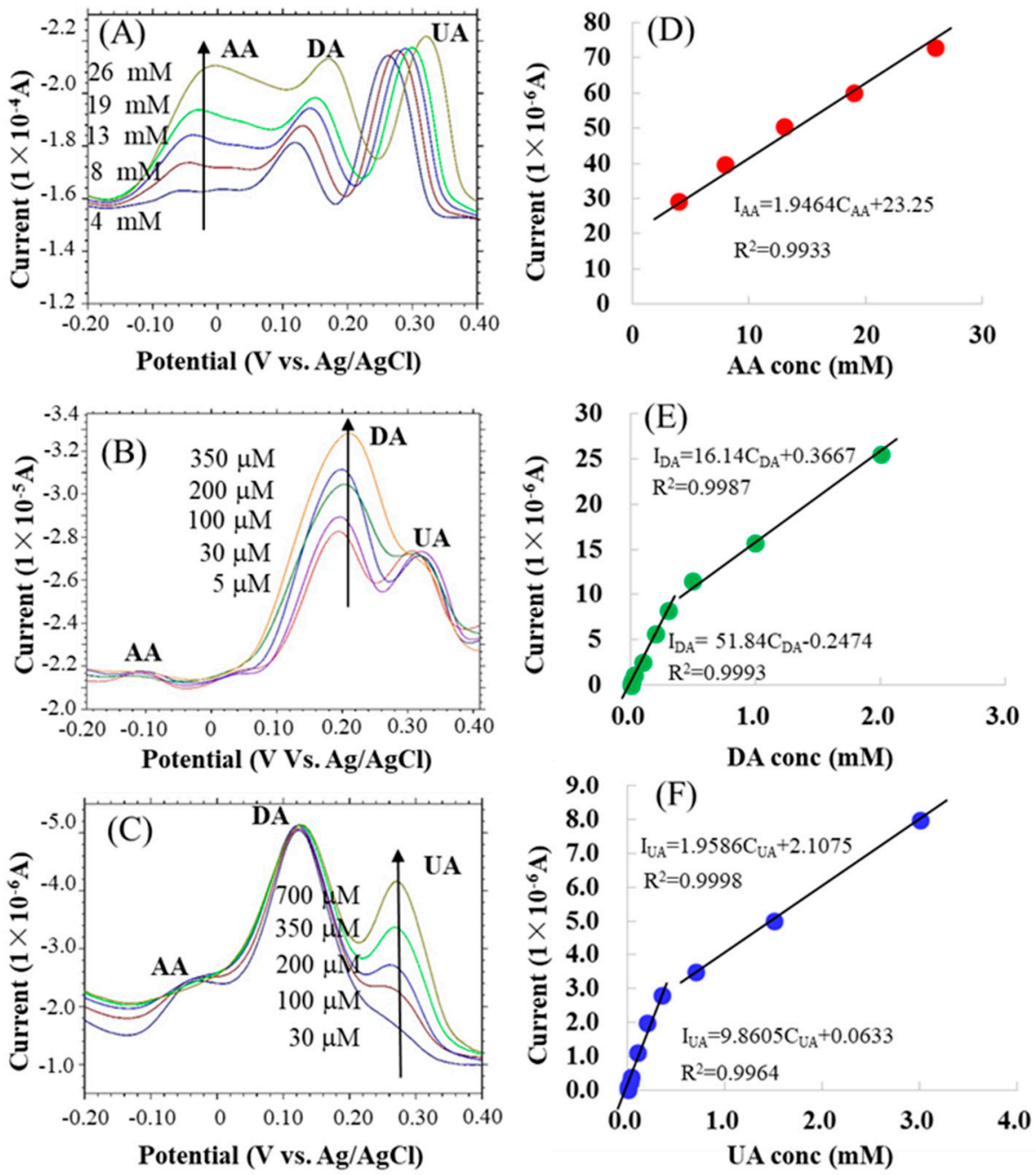

Figure 3. DPV curves of CB-CNT/PI/GCE in $0.1 \mathrm{M}$ PBS ( $\mathrm{pH} 7.0$ ) with the AA/DA/UA mixtures: (A) 4-26 mM AA + $0.005 \mathrm{mM} \mathrm{DA}+0.1 \mathrm{mM} \mathrm{UA}$; (B) $5.0 \mathrm{mM} \mathrm{AA}+5-350 \mu \mathrm{M} \mathrm{DA}+1 \mathrm{mM} \mathrm{UA}$; (C) $1.0 \mathrm{mM} \mathrm{AA}+0.1 \mathrm{mM} \mathrm{DA}+30-700 \mu \mathrm{M}$ UA. (D-F) The oxidation current of substrates (I) vs. concentrations $(\mathrm{C})$.

\subsection{Electrochemical Determination of $A A, D A$, and $U A$}

The steady-state amperometric responses of the CB-CNT/PI/GCE to AA, DA, and UA are presented in Figure 4. Different concentrations of analytes were added into a stirring 0.1 M PBS ( $\mathrm{pH}$ 7.0) with a fixed potential. The corresponding plots of the currents and analyte concentrations are calculated in Figure 4D-F. From the amperometric curve for sensing AA in Figure 4A, the linear relationship between the oxidation current and concentration is obtained in the range of 0.1-5 mM. The linear regression equation is $\mathrm{I}_{\mathrm{AA}}=0.9504 \mathrm{C}_{\mathrm{AA}}-0.0146$, with a correlation coefficient of $\mathrm{R}^{2}=0.998$ $(n=3)$. The detection limit of AA was found to be $75 \mu \mathrm{M}$. Figure $4 \mathrm{~B}$ shows the amperometric response of DA at the potential of $+0.2 \mathrm{~V}$. The linear range of $\mathrm{DA}$ is from 0.08 to $3 \mathrm{mM}$, with the linear regression equation is $\mathrm{I}_{\mathrm{DA}}=0.9709 C_{\mathrm{DA}}+0.0244$, a correlation coefficient of $R^{2}=0.9893(\mathrm{n}=3)$. The detection limit of DA was found to be $60 \mu \mathrm{M}$. Similarly, Figure 4C exhibits the amperometric response of UA at a potential of $+0.35 \mathrm{~V}$. The linear relationship of UA was determined for UA concentrations ranging from 0.01 to $1 \mathrm{mM}$. The regression equation is $\mathrm{I}_{\mathrm{UA}}=3.2261 \mathrm{C}_{\mathrm{UA}}+0.2878$, a correlation coefficient of $R^{2}=0.9963(n=3)$. The detection limit of UA was found to be $8.8 \mu M$. The insets in Figure $4 D-F$ are the calibration curves for low concentrations of AA, DA, and UA. 

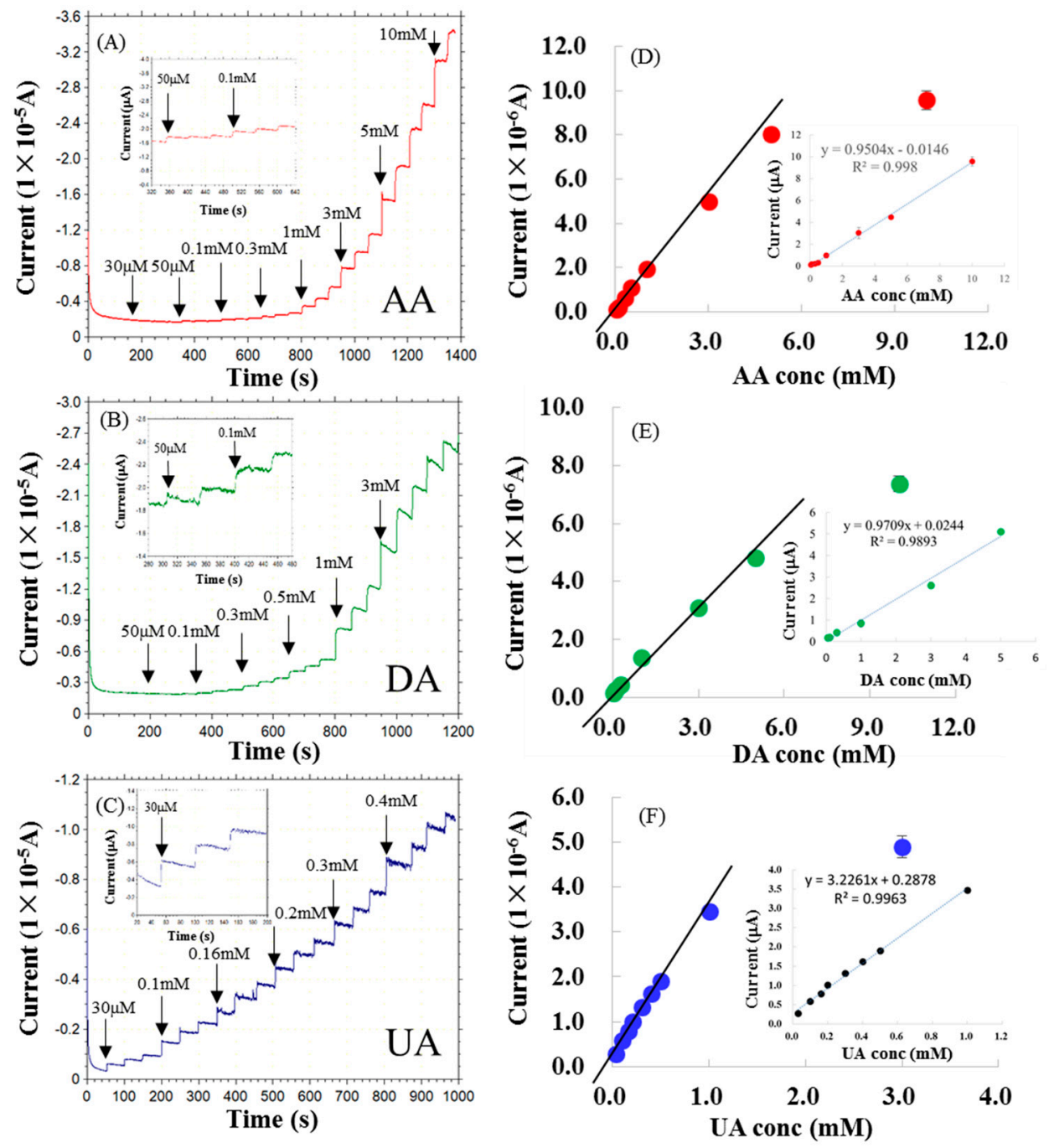

Figure 4. Steady-state amperometric responses of the CB-CNT/PI/GCE for the subsequent addition of (A) AA $(-0.05 \mathrm{~V}),($ B) DA $(+0.2 \mathrm{~V})($ C) UA $(+0.35 \mathrm{~V})$ in a $0.1 \mathrm{M}$ PBS (pH 7.0). The oxidation curves vs. the concentration of various substances: (D) AA, (E) DA, and (F) UA.

\subsection{Selectivity, Reproducibility, and Long-Term Stability}

Selectivity is a key factor to evaluate the performance of sensors. Effect of several potential interferential species on the determination of AA, DA, and UA were carried out. When 10-times concentration $(3 \mathrm{mM})$ of $\mathrm{FeCl}_{3}, \mathrm{NH}_{4} \mathrm{Cl}, \mathrm{NaCl}, \mathrm{KCl}$, glucose, fructose, maltose, citric acid, urea, $\mathrm{H}_{2} \mathrm{O}_{2}$, and $\mathrm{Na}_{2} \mathrm{SO}_{4}$ were added into the mixture of $0.3 \mathrm{mM} \mathrm{AA}, 0.3 \mathrm{mM} \mathrm{DA}$, and $0.3 \mathrm{mM} \mathrm{UA}$, no obvious interference can be observed (Table 1), indicating the good anti-interference ability of the CB-CNT/PI/GCE. To check the reproducibility of the electrode preparation, three electrodes were prepared under the same conditions. It was found that the relative standard deviation (RSD, $n=3$ ) was $3.1 \%$ for these electrodes, which shows high repeatability of the fabrication method. In addition, to evaluate the practical usage of the present sensor, the long-term stability of the CB-CNT/PI/GCE was investigated by continuous detecting of these three substances every five days for a month. When not in use, the sensor was put in a laboratory in air conditioning. Even after 1 month storage, it remained $95.6 \%$ of initial current. These sufficient performances are satisfied because of the stable characteristics of PI. 
Table 1. Results of interference study on the response of ascorbic acid (AA), dopamine (DA), and uric acid (UA).

\begin{tabular}{cccc}
\hline Interferent & $\begin{array}{c}\text { Current Intensity } \\
\text { Variation (AA) }\end{array}$ & $\begin{array}{c}\text { Current Intensity } \\
\text { Variation (DA) }\end{array}$ & $\begin{array}{c}\text { Current Intensity } \\
\text { Variation (UA) }\end{array}$ \\
\hline $\mathrm{FeCl}_{3}$ & $0.99 \%$ & $2.61 \%$ & $0.69 \%$ \\
$\mathrm{NH}_{4} \mathrm{Cl}$ & $-2.63 \%$ & $-6.29 \%$ & $-1.82 \%$ \\
$\mathrm{NaCl}$ & $0.74 \%$ & $2.39 \%$ & $0.51 \%$ \\
$\mathrm{KCl}$ & $0.63 \%$ & $1.66 \%$ & $0.43 \%$ \\
Urea & $0.43 \%$ & $1.26 \%$ & $0.65 \%$ \\
Citric acid & 0 & 0 & 0 \\
Glucose & 0 & 0 & 0 \\
Fructose & 0 & 0 & 0 \\
$\mathrm{Maltose}$ & 0 & 0 & 0 \\
$\mathrm{H}_{2} \mathrm{O}_{2}$ & 0 & 0 & 0 \\
$\mathrm{Na}_{2} \mathrm{SO}_{4}$ & 0 & 0 & 0 \\
\hline
\end{tabular}

\subsection{Real Sample Analysis}

The practical application for determination of AA, UA, and DA in human urine samples was carried out to check the performance of the present sensor. A fresh urine sample was prepared by 50-fold dilution of urine with PBS ( $\mathrm{pH} 7$ ). Amperometry technique was used in an electrochemical cell containing $400 \mu \mathrm{L}$ of urine sample and $20 \mathrm{~mL}$ of PBS. Different concentration of AA, DA, and UA was added into the sample. Table 2 summarizes the collected data in which recovery ranged with $90.7 \%$ to $108.2 \%$. The results indicate that the CB-CNT/PI/GCE can be applied successfully for the electrochemical detection of AA, DA, and UA in real biological samples. The PI would effectively suppress the biofouling of the electrode surface, and allows the detection in body samples, which is one of the notable advantages of this system. Table 3 summarizes the analytical performance of various electrodes for the electrochemical determination of AA, DA, and UA.

Table 2. Determination of AA, DA, and UA in human urine samples $(n=3)$.

\begin{tabular}{|c|c|c|c|c|c|}
\hline Sample & & Add $\left(\mu \mathrm{mol} \mathrm{L}{ }^{-1}\right)$ & Found $\left(\mu \mathrm{mol} \mathrm{L}^{-1}\right)$ & RSD (\%) & Recovery (\%) \\
\hline \multirow{3}{*}{ Urine 1} & $\mathrm{AA}$ & 200 & 204.0 & 2.5 & 102.0 \\
\hline & DA & 100 & 107.5 & 1.9 & 108.0 \\
\hline & UA & 50 & 49.9 & 3.2 & 99.8 \\
\hline \multirow{3}{*}{ Urine 2} & $\mathrm{AA}$ & 200 & 195.8 & 2.4 & 97.9 \\
\hline & $\mathrm{DA}$ & 100 & 90.7 & 3.2 & 90.7 \\
\hline & UA & 50 & 52.1 & 3.5 & 104.2 \\
\hline \multirow{3}{*}{ Urine 3} & $\mathrm{AA}$ & 200 & 192.8 & 2.8 & 96.4 \\
\hline & DA & 100 & 107.4 & 2.7 & 107.4 \\
\hline & UA & 50 & 54.1 & 3.1 & 108.2 \\
\hline
\end{tabular}


Table 3. Comparison of analytical performances the carbon black-carbon nanotube (CB-CNT)/polyimide (PI)/glassy carbon electrode (GCE) with other reported materials for electrochemical determination of AA, DA, and UA.

\begin{tabular}{|c|c|c|c|c|c|c|c|c|c|c|}
\hline \multirow{2}{*}{ Electrode } & \multirow{2}{*}{ Method } & \multicolumn{3}{|c|}{ Linear Range $(\mu \mathrm{M})$} & \multicolumn{3}{|c|}{ Detection Limit $(\mu \mathrm{M})$} & \multicolumn{2}{|c|}{ Peak Separation $(\mathrm{mV})$} & \multirow{2}{*}{ Refs. } \\
\hline & & AA & DA & UA & AA & DA & UA & AA-DA & DA-UA & \\
\hline $\mathrm{ERGO}^{\mathrm{EGCE}}{ }^{\mathrm{a}}$ & DPV & 300-2000 & $0.5-60$ & $0.5-60$ & 300 & 0.5 & 0.5 & 240 & 130 & [33] \\
\hline $\mathrm{MoS}_{2} / \mathrm{PEDOT} / \mathrm{GCE}^{\mathrm{b}}$ & DPV & $20-140$ & $1-80$ & $2-25$ & 5.83 & 0.52 & 0.95 & 210 & 150 & [9] \\
\hline $\mathrm{ZnO} / \mathrm{RM} / \mathrm{GCE}^{\mathrm{d}}$ & $\mathrm{CV}$ & $15-240$ & $6-960$ & $50-800$ & 1.4 & 0.7 & 4.5 & - & - & [36] \\
\hline $\mathrm{Fe}_{3} \mathrm{O}_{4} / \mathrm{rGO} / \mathrm{GCE}^{\mathrm{e}}$ & DPV & $1000-9000$ & $0.5-10$ & - & 0.12 & 0.42 & - & 210 & - & [37] \\
\hline nanoSnO$_{2} / \mathrm{MWCNTs}_{\mathrm{CPE}}{ }^{\mathrm{f}}$ & DPV & $0.1-5$ & $0.3-50$ & $3-200$ & 50 & 0.03 & 1.0 & 224 & 165 & [38] \\
\hline \multirow{2}{*}{ CB-CNT/PI/GCE } & DPV & $1000-24000$ & $3-300$ & $5-500$ & 154 & 1.86 & 3.0 & 166 & 148 & This \\
\hline & amperometry & $100-5000$ & $80-3000$ & $10-1000$ & 75 & 60 & 8.8 & - & - & work \\
\hline
\end{tabular}

${ }^{a}$ electrochemically reduced graphene oxide/Glassy carbon electrode (GCE); ${ }^{\mathrm{b}} \mathrm{MoS}_{2} / \mathrm{PEDOT}$ nanocomposite modified GCE; ${ }^{c}$ MWCNT-PEDOT film modified electrode; ${ }^{d}$ zinc oxide/redox mediator modified GCE; e chitosan-graphene modified GCE; ${ }^{\mathrm{f}} \mathrm{SnO}_{2}$ nanoparticles/multi-walled carbon nanotubes/carbon paste electrode;

${ }^{\mathrm{g}}$ platinum nanoparticle-decorated graphene and carbon nanotube; ${ }^{\mathrm{h}}$ graphene sheets and gold nanoparticles modified carbon fiber electrode; differential pulse voltammetry (DPV); cyclic voltammetry (CV).

\section{Conclusions}

The CB and CNT-co-doped PI was modified on the glassy carbon electrode, and as-prepared electrode (CB-CNT/PI/GCE) was successfully utilized for the simultaneous detection of AA, UA, and DA. The CB-CNT/PI/GCE exhibited high electrocatalytic activities towards the oxidation of AA, $\mathrm{DA}$, and UA, and sufficient peak separation between AA, DA, and UA was observed with CV and DPV. The CB-CNT/PI/GCE showed sufficient selectivity and stability, and was applicable to the analysis in a human urine sample. The large capacity of PI and high surface area of CB and CNT make it a promising candidate for electrocatalytic applications and biomedical applications.

Supplementary Materials: The following are available online at http://www.mdpi.com/1996-1944/11/ 9/1691/s1, Figure S1: Synthesis of dinitro compound and diamine monomer, Figure S2: ${ }^{1} \mathrm{H}-\mathrm{NMR}$ spectra of 9,9'-Bis[4-(4-nitro-2-hydroxybenzoxyl) phenyl] fluorene (BNHOPF), Figure S3: ${ }^{1} \mathrm{H}-\mathrm{NMR}$ spectra of 9,9'-Bis[4-(4-amino-2-hydroxybenzoxyl) phenyl] fluorene (BAHOPF), Figure S4: Synthesis procedures of polyimide; Figure S5: FT-IR spectras of dinitro compound (a) and diamine monomer(b), Figure S6: FT-IR of polyimide, Figure S7: XRD of polyimide.

Author Contributions: Y.W. conceived and designed the experiment, wrote the paper; T.Y. performed the synthesis and detection experiments; Z.Z. contributed the analyzing the data; Y.H. and D.T. contributed to manuscript version.

Funding: The authors gratefully acknowledge the financial support from the Natural Science Foundation of Liaoning Province (No. 20170540464), the Department of Education of Liaoning (No. 2017LNQN05), and the Foundation of University of Science and Technology, Liaoning (No. 2016RC12).

Conflicts of Interest: The authors declare no conflict of interest.

\section{References}

1. Wu, W.C.; Chang, H.W.; Tsai, Y.C. Electrocatalytic detection of dopamine in the presence of ascorbic acid and uric acid at silicon carbide coated electrodes. Chem. Commun. 2011, 47, 6458-6460. [CrossRef] [PubMed]

2. Zhang, A.; Neumeyer, J.L.; Baldessarini, R.J. Recent progress in development of dopamine receptor subtype-selective agents: Potential therapeutics for neurological and psychiatric disorders. Chem. Rev. 2007, 107, 274-302. [CrossRef] [PubMed]

3. Palomäki, T.; Chumillas, S.; Sainio, S.; Protopopova, V.; Kauppila, M.; Koskinen, J.; Climent, V.; Feliu, J.M.; Laurila, T. Electrochemical reactions of catechol, methylcatechol and dopamine at tetrahedral amorphous carbon (ta-C) thin film electrodes. Diam. Relat. Mater. 2015, 59, 30-39. [CrossRef]

4. Chumillas, S.; Figueiredo, M.C.; Climent, V.; Feliu, J.M. Study of dopamine reactivity on platinum single crystal electrode surfaces. Electrochim. Acta 2013, 109, 577-586. [CrossRef] 
5. Mo, J.W.; Ogorevc, B. Glassy carbon electrode modified with poly(dibromofluorescein) for the selective determination of dopamine and uric acid in the presence of ascorbic acid. Michrochim. Acta 2012, 178, 123-130. [CrossRef]

6. Wang, Y.; Hasebe, Y.J. Uricase-adsorbed carbon-felt reactor coupled with a peroxidase-modified carbon-felt-based $\mathrm{H}_{2} \mathrm{O}_{2}$ detector for highly sensitive amperometric flow determination ofuric acid. J. Pharm. Biomed. Anal. 2012, 57, 125-132. [CrossRef] [PubMed]

7. Guilbault, G.G. Analytical Uses of Immoblised Enzymes; Marcel Dekker: New York, NY, USA, 1984.

8. Yang, Y.J.; Li, W. CTAB functionalized graphene oxide/multiwalled carbon nanotube composite modified electrode for the simultaneous determination of ascorbic acid, dopamine, uric acid and nitrite. Biosens. Bioelectron. 2014, 56, 300-306. [CrossRef] [PubMed]

9. Li, Y.; Lin, H.C.; Peng, H.; Qi, R.J.; Luo, C.H. A glassy carbon electrode modified with $\mathrm{MoS}_{2}$ nanosheets and poly(3,4-ethylenedioxythiophene) for simultaneous electrochemical detection of ascorbicacid, dopamine and uric acid. Microchim. Acta 2016, 183, 2517-2523. [CrossRef]

10. Jadon, N.; Jain, R.; Sharma, S.; Singh, K. Recent trends in electrochemical sensors for multianalyte detection-A review. Talanta 2016, 161, 894-916. [CrossRef] [PubMed]

11. Zhu, S.Y.; Li, H.J.; Niu, W.X.; Xu, G.B. Simultaneous electrochemical determination of uric acid, dopamine, and ascorbic acid at single-walled carbon nanohorn modified glassy carbon electrode. Biosens. Bioelectron. 2009, 25, 940-943. [CrossRef] [PubMed]

12. Sun, C.L.; Chang, C.T.; Lee, H.H.; Zhou, J.G.; Wang, J.; Sham, T.K.; Pong, W.F. Microwave-Assisted Synthesis of a Core-Shell MWCNT/GONR Heterostructure for the Electrochemical Detection of Ascorbic Acid, Dopamine, and Uric Acid. ACS Nano 2011, 10, 7788-7795. [CrossRef] [PubMed]

13. Liu, X.F.; Wei, S.P.; Chen, S.H.; Yuan, D.H.; Zhang, W. Graphene-multiwall carbon nanotube-gold nanocluster composites modified electrode for the simultaneous determination of ascorbic acid, dopamine, and uric acid. Appl. Biochem. Biotechnol. 2014, 173, 1717-1726. [CrossRef] [PubMed]

14. Taleb, M.; Ivanov, R.; Bereznev, S.; Kazemi, S.H.; Hussainova, I. Ultra-sensitive voltammetric simultaneous determination of dopamine, uric acid and ascorbic acid based on a graphene-coated alumina electrode. Microchim. Acta 2017, 184, 4603-4610. [CrossRef]

15. Laurila, T.; Sainio, S.; Caro, M.A. Hybrid carbon based nanomaterials for electrochemical detection of biomolecules. Prog. Mater. Sci. 2017, 88, 499-594. [CrossRef]

16. Wu, F.; Huang, T.; Hu, Y.J.; Yang, X.; Ouyang, Y.J.; Xie, Q.J. Differential pulse voltammetric simultaneous determination of ascorbic acid, dopamine and uric acid on a glassy carbon electrode modified with electroreduced graphene oxide and imidazolium groups. Microchim. Acta 2016, 183, 2539-2546. [CrossRef]

17. Mei, L.P.; Feng, J.J.; Wu, L.; Chen, J.R.; Shen, L.G.; Xie, Y.L.; Wang, A.J. A glassy carbon electrode modified with porous $\mathrm{Cu}_{2} \mathrm{O}$ nanospheres on reduced graphene oxide support for simultaneous sensing of uric acid and dopamine with high selectivity over ascorbic acid. Microchim. Acta 2016, 183, 2039-2046. [CrossRef]

18. Wu, L.N.; Tan, Y.L.; Wang, L.; Sun, S.N.; Qu, Z.Y.; Zhang, J.M.; Fan, Y.J. Dopamine sensor based on a hybrid material composed of cuprous oxide hollow microspheres and carbon black. Microchim. Acta 2015, 182, 1361-1369. [CrossRef]

19. Łuczak, T.; Osińska, M. New self-assembled layers composed with gold nanoparticles, cysteamine and dihydrolipoic acid deposited on bare gold template for highly sensitive and selective simultaneous sensing of dopamine in the presence of interfering ascorbic and uric acids. J. Solid State Electrochem. 2017, 21, 747-758. [CrossRef]

20. Zheng, X.; Zhou, X.; Ji, X.; Lin, R.; Lin, W. Simultaneous determination of ascorbic acid, dopamine and uric acid using poly(4-aminobutyric acid) modified glassy carbon electrode. Sens. Actuators B 2013, 178, 359-365. [CrossRef]

21. Zheng, Y.J.; Huang, Z.J.; Zhao, C.F.; Weng, S.H.; Zheng, W.; Lin, X.H. A Gold electrode with a flower-like gold nanostructure for simultaneous determination of dopamine and ascorbic acid. Microchim. Acta 2013, 180, 537-544. [CrossRef]

22. Poh, W.C.; Loh, K.P.; Zhang, W.D.; Sudhiranjan, T.; Ye, J.S.; Sheu, F.S. Biosensing properties of diamond and carbon nanotubes. Langmuir 2004, 20, 5484-5492. [CrossRef] [PubMed]

23. Nasri, Z.; Shams, E. Application of silica gel as an effective modifier for the voltammetric determination of dopamine in the presence of ascorbic acid and uric acid. Electrochim. Acta 2009, 54, 7416-7421. [CrossRef] 
24. Lacroix, M.; Bianco, P.; Lojou, E. Modified random assembly of microelectrodes for the selective electrochemical detection of dopamine. Electroanalysis 1999, 11, 1068-1076. [CrossRef]

25. Shen, X.; Xia, X.H.; Du, Y.L.; Wang, C.M. Electroless deposition of Au nanoparticles on reduced graphene oxide/polyimide film for electrochemical detection of hydroquinone and catechol. Front. Mater. Sci. 2017, 11, 262-270. [CrossRef]

26. Li, H.; Cheng, G.; Xu, G.W.; Luo, L. Influence of polyimide on thermal stress evolution in polyimide/Cu think film composite. J. Mater. Sci. Mater. Electron. 2016, 27, 8325-8331. [CrossRef]

27. Ma, X.H.; Swaidan, R.; Belmabkhout, Y.; Zhu, Y.H.; Litwiller, E.; Jouiad, M.; Pinnau, L.; Han, Y. Synthesis and gas transport properties of hydroxyl-functionalized polyimides with intrinsic microporosity. Macromolecules 2012, 45, 3841-3849. [CrossRef]

28. Ensafi, A.A.; Taei, M.; Khayamian, T.; Arabzadeh, A. Highly selective determination of ascorbic acid, dopamine, and uric acid by differential pulse voltammetry using poly (sulfonazo III) modified glassy carbon electrode. Sens. Actuators B 2010, 147, 213-221. [CrossRef]

29. Ping, J.; Wu, J.; Wang, Y.; Ying, Y. Simultaneous determination of ascorbic acid, dopamine and uric acid using high-performance screen-printed graphene electrode. Biosens. Bioelectron. 2012, 34, 70-76. [CrossRef] [PubMed]

30. Jiang, J.; Du, X. Sensitive electrochemical sensors for simultaneous determination of ascorbic acid, dopamine, and uric acid based on Au@Pd-reduced grapheme oxide nanocomposites. Nanoscale 2014, 6, 11303-11309. [CrossRef] [PubMed]

31. Yue, H.Y.; Huang, S.; Chang, J.; Heo, C.; Yao, F.; Adhikari, S.; Gunes, F.; Liu, L.C.; Lee, T.H.; Oh, E.S.; et al. $\mathrm{ZnO}$ Nanowire arrays on 3D hierarchical graphene foam: Biomarker detection of parkinson's disease. ACS Nano 2014, 8, 1639-1646. [CrossRef] [PubMed]

32. Su, C.H.; Sun, C.L.; Liao, Y.C. Printed combinatorial sensors for simultaneous detection of ascorbic acid, uric acid, dopamine, and nitrite. ACS Omega 2017, 2, 4245-4252. [CrossRef] [PubMed]

33. Yang, L.; Liu, D.; Huang, J.; You, T. Simultaneous determination of dopamine, ascorbic acid and uric acid at electrochemically reduced graphene oxide modified electrode. Sens. Actuators B 2014, 193, 166-172. [CrossRef]

34. Lin, K.C.; Tsai, T.H.; Chen, S.M. Performing enzyme-free $\mathrm{H}_{2} \mathrm{O}_{2}$ biosensor and simultaneous determination for AA, DA, and UA by MWCNT-PEDOT film. Biosens. Bioelectron. 2010, 26, 608-614. [CrossRef] [PubMed]

35. Ramakrishnan, S.; Pradeep, K.R.; Raghul, A.; Senthilkumar, R.; Rangarajan, M.; Kothurkar, N.K. One-step synthesis of Pt-decorated graphene-carbon nanotubes for the electrochemical sensing of dopamine, uric acid and ascorbic acid. Anal. Methods 2015, 7, 779-786. [CrossRef]

36. Tang, C.F.; Kumar, S.A.; Chen, S.M. Zinc oxide/redox mediator composite films-based sensor for electrochemical detection of important biomolecules. Anal. Biochem. 2008, 380, 174-183. [CrossRef] [PubMed]

37. Teo, P.S.; Alagarsamy, P.; Huang, N.M.; Lim, H.N.; Yusran, S. Simultaneous electrochemical detection of dopamine and ascorbic acid using an iron oxide/reduced graphene oxide modified glassy carbon electrode. Sensors 2014, 14, 15227-15243. [CrossRef]

38. Sun, D.; Zhao, Q.; Tan, F.; Wang, X.; Gao, J. Simultaneous detection of dopamine, uric acid, and ascorbic acid using $\mathrm{SnO}_{2}$ nanoparticles/multi-walled carbon nanotubes/carbon paste electrode. Anal. Methods 2012, 4, 3283-3289. [CrossRef]

39. Du, J.; Yue, R.; Ren, F.; Yao, Z.; Jiang, F.; Yang, P. Simultaneous determination of uric acid and dopamine using a carbon fiber electrode modified by layer-by-layer assembly of graphene and gold nanoparticles. Gold Bull. 2013, 46, 137-144. [CrossRef]

(C) 2018 by the authors. Licensee MDPI, Basel, Switzerland. This article is an open access article distributed under the terms and conditions of the Creative Commons Attribution (CC BY) license (http:// creativecommons.org/licenses/by/4.0/). 